Research Article

\title{
Field-Obtained Soil-Water Characteristic Curves of KPK Expansive Soil and Their Prediction Correlations
}

\author{
Bakht Zamin (D), ${ }^{1}$ Hassan Nasir ${ }^{D},{ }^{1}$ Khalid Mehmood, ${ }^{2}$ and Qaiser Iqbal ${ }^{2}$ \\ ${ }^{1}$ Civil Engineering Department, CECOS University of IT \& Emerging Sciences, Peshawar, Pakistan \\ ${ }^{2}$ Civil Engineering Department, Sarhad University of Science \& Information Technology (SUIT), Peshawar, Pakistan
}

Correspondence should be addressed to Bakht Zamin; bakhtzamin82@gmail.com and Hassan Nasir; shassannasir@gmail.com

Received 4 February 2020; Revised 28 September 2020; Accepted 20 October 2020; Published 21 November 2020

Academic Editor: Fan Gu

Copyright (C) 2020 Bakht Zamin et al. This is an open access article distributed under the Creative Commons Attribution License, which permits unrestricted use, distribution, and reproduction in any medium, provided the original work is properly cited.

Expansive clays are found worldwide in arid and semiarid regions. Such soils are considered a natural hazard for civil engineering infrastructures especially when they are lightly loaded. Expansive soils are often unsaturated due to the high absorption capacity of moisture. The damaging effect of expansive soils is intimately related to the distinctive soil-water characteristic in the surficial soil layers subjected to wetting-drying cycles. The soil-water characteristic curve (SWCC) also known as the water-retention curve shows the fluctuation of suction with the moisture content. It is one of the key parameters that have been developed and used by soil engineers for studying the properties of partially saturated soils. Currently, the SWCCs produced by most of the researchers are grounded on lab testing which is quite different from the field-obtained curves. In the current study, the SWCCs for Karak expansive soil have been obtained from in situ testing (field). For this purpose, three sites were selected at Amberi Village (Karak) for instrumentation. An open trench of six-foot depth was excavated in each site and instrumented. Electrical resistivity sensors (G-blocks) and tensiometers were used for matric suction measurements. The gravimetric moisture content was measured with the help of moisture sensors calibrated with a speedy moisture meter. To check the fluctuation of moisture and suction, these instruments were installed at three different depths, that is, 0-2, 2-4, and 4-6 feet. Based on results, the maximum suction of $705.79 \mathrm{kPa}$ was observed in the site " $\mathrm{A}$ " in $0-2$-foot depth (near the ground surface) with a moisture content of 15 percent. The variations in suction and moisture content follow the almost same trend at low suction; however, the trend was slightly different at the moderate suction range. The measured suction showed a strong correlation with the free swell index (FSI) and moisture content. It was found that the upper layers of expansive soil have high suction than lower layers due to more exposure to the environmental agencies and low density.

\section{Introduction}

Expansive soil is clayey soil in nature which undergoes large volume changes upon changing in the moisture content. Such soils may be found in arid and semiarid areas causing distresses in the lightly loaded structures. These soils tend to expand and contract due to sessional variation of moisture, resulting in the uneven movement in the shallow depths. These soils are highly plastic due to the presence of clayey minerals like montmorillonite which absorb a large amount of water. Swelling and shrinkage are associated with the presence of varieties of minerals such as montmorillonite, kaolinite, and illite groups of minerals in these soils [1]. The presence of swelling clay can be identified well in the field from the surface desiccation cracks as shown in Figure 1. Problematic soils often exist near the ground surface (shallow depth); owing to high negative pore-water pressure, it tends to produce serious problems in geotechnical engineering. The most common types of such soils are expansive soils, collapsible soils, and residual soils [2]. Expansive soils are distributed worldwide and provoke distresses in the light structures, that is, buildings, pavements, and slopes, and have been conceived in numerous countries around the world. The financial loss occasioned by expansive soil is comparatively larger than the combined loss of flood, tornadoes, earthquakes, and hurricanes. The problems associated with expansive soil mainly happen due to the changes in moisture content in the upper few meters and lacking in deep layers [3]. 

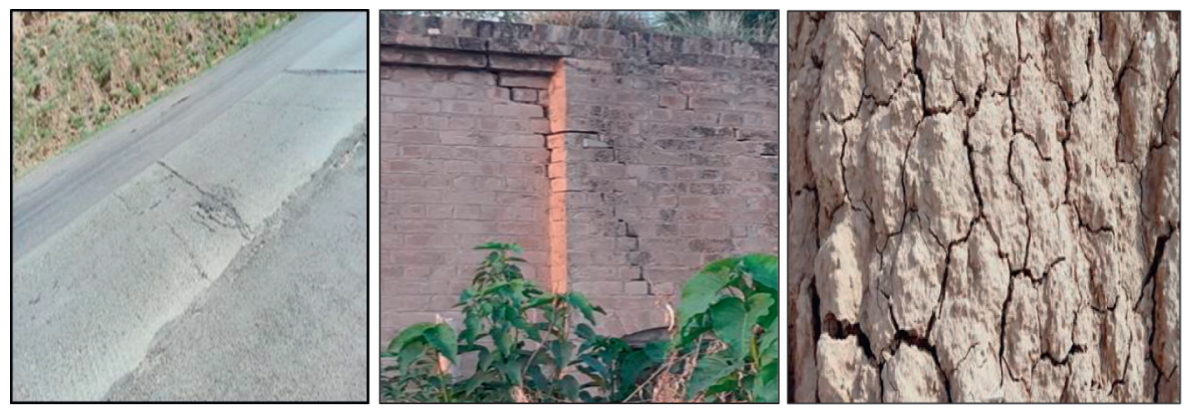

Figure 1: Damages due to the presence of expansive soil and desiccation cracks.

The water content in these upper layers is significantly influenced by climatic and environmental factors and is generally termed the zone of seasonal fluctuations or active zone. The damaging effect of expansive soils is intimately related to the distinctive soil-water characteristic in the surficial soil layers subjected to wetting-drying cycles. In the dry period, evapotranspiration provokes a loss of moisture in surficial layers, and expansive soil contracts and cracks, while in the wet period, rainwater percolates in soil, increasing the moisture content and reducing the suction in the upper layers, resulting in a decrease in the shear strength and bulging of soil or growing of swelling pressure in captive circumstances. Field studies indicate that the soil-water relationship caused by sessional wetting-drying rounds is very complicated and comprises the joint effects between the fluctuation in moisture content, suction, stress, distortion, and shear strength parameters $[4,5]$. Surficial soils are frequently identified as challenging soils, but most of the severe issues are impeded for soil engineers due to the presence of suction in these soils.

Soil-water characteristic curve (SWCC) is an important relationship that correlates the soil suction with moisture content present in the soils. This curve can be obtained from either laboratory testing or in situ instrumentation. The SWCC is also used for obtaining model parameters in the framework of unsaturated soil mechanics. These parameters may be used for obtaining some fundamental properties (mechanical and hydraulic) of soils.

As some of the reigns of Pakistan fall in the semiarid zone, swelling clays of low and high plasticity exist abundantly in these areas. The presence of swelling clay has been reported in locations like Kohat, Karak, Nowshera Bunnu, Charassada, and Dera Ismail Khan of Khyber Pakhtunkhwa Province (KPK), Pakistan. These soils have caused some damages to the boundary walls of various buildings and flexible pavements in the KPK Province, Pakistan, as shown in Figure 1. In the current study, SWCCs for local expansive soil were established from the field instrumentation. For this purpose, tensiometers, gypsum blocks, and moisture sensors were installed in open trenches in Karak's expansive soil. Swelling behavior is studied using free swell index tests on collected samples from the open trenches. The major reason for studying the swelling and suction behavior of expansive soil rests on the fact that both these features are greatly dependent on the physical, mineralogical, and environmental characteristics of the soil. The appurtenance of both of these features with the change in moisture content due to the change in weather is well depicted in the past $[6,7]$.

The SWCCs obtained from actual field-testing are quite different from those obtained in the laboratory testing. Fieldobtained curves mostly lie between the wetting and drying curves of the laboratory tests [8]. Applied stresses can change the shapes of SWCCs considerably. Similarly, confinement condition is also an important factor responsible for the change of shape of SWCCs. The field measured curve for $30 \mathrm{~cm}$ depth is nearly equal to the wetting curve measured in the laboratory when no vertical load is applied $[8,9]$. Most of the research work related to suction and swelling behavior of expansive soils in the past is based on laboratory testing only, which lacks the true representation of the field environment. Furthermore, the field suction measurement involved a very expansive instrumentation technique like a time-domain reflectometer (TDR) method, thermal conductivity sensor (TCS), and so on. The main objective of the current study is to check the behavior of local expansive soil in the framework of unsaturated soil mechanics and develop some correlation equation for subsequent use. For this purpose, field instrumentation was carried out using a low-cost technique for measuring indirect matric potential (suction) and gravimetric moisture content in the field at shallow depths. Statistical analysis was carried out using the Statistical Package for Social Sciences (SPSS). Based on the collected data, some regression equations have been developed for predicting soil suction from the measured moisture contents and free swell index values.

\section{Literature Review and Background}

The matric suction of soil is one of the most useful properties in the study of unsaturated soil mechanics. It closely relates to the volumetric or gravimetric water content. The matric potential is very useful in studying the hydrological processes in the soil, such as evapotranspiration, availability of water for plants, and modeling the gas and water flow in unsaturated soil [10]. Furthermore, it is also applied in the strength and deformation characteristic of unsaturated soil and determining the physical response of various soil at different moisture contents [11]. The consolidation type pressure plate is widely used for measuring the soil matric suction in the labs. The pressure plate apparatus is not only expansive but also time-consuming. Moreover, it is not suitable for measuring the suction of the field [12]. 
Tensiometers are the instrument generally used for measuring the soil suction. This is a low-cost technique but unsuitable for very dry soil [13]. Similarly, commercially available sensors like thermal and electrical resistance type are also used for measuring matric potential in the field. Gypsum, blocks sensors among the porous blocks, have the advantage that they tend to buffer the soil salinity, thereby decreasing the effect of salts on matric suction. This process is done due to the soluble nature of gypsum and it reduces the useful life of blocks. Therefore, gypsum blocks can be useful for short-term measurement. In the case of alkaline or neutral soil, these blocks have a life of 5 years, but it should be replaced after 2-3 years in the case of acidic soil. Gypsum probes and eight other types of sensors have been used for experimental testing in the research site, Agriculture and Agri-Food Canada [14]. Mercury manometer tensiometers and granular matrix sensors have also been used for the hydrologic monitoring in the erosion plots at Avelar Experimental Campus, Brazil. Both tensiometers and matrix sensors can be used for reliable measurements of matric potential. However, below $-70 \mathrm{kPa}$, soil suction curves differ due to the low range of tensiometers. The suction measured with both instruments was similar [15]. Interestingly, if gypsum block sensors are separately calibrated, the obtained suction results will be close to that measured with the filter paper method [16].

\section{Samples Collection and Testing Procedure}

In this research work, representative disturbed samples were collected from three sites of Karak expansive soils. During sampling, an open trench of six-foot depth (shallow depth), four-foot length, and two-foot width was excavated in each site as shown in Figure 2(a). The excavated soil from the top, middle, and bottom of the trench was packed in polythene bags, labeled, and shifted to the soil mechanics laboratory for basic testing. The moisture content was assessed according to ASTM 2216 guidelines. For grinding the hard and dry chunks, the ball-grinding method is used. This method involved collision and impact action of steel balls, which can mix and grind the materials. Consequently, better dispersion may be achieved by the wear action between the rapidly rotating bodies and inner sides of the drum $[17,18]$.

3.1. Gradation, Specific Gravity, and Consistency Limits. The grain size distribution curve (GSD) obtained from sieve and hydrometer analysis under the ASTM D422-63 (2002) test methodology is shown in Figure 3. The gradation curve shows that the sample contained mostly fine grain and limited coarse fraction.

Details of the basic engineering properties of the expansive soils used in this study are mentioned along with sample designation in Table 1. For finding specific gravity $\left(G_{s}\right)$ of the soil, a simple pycnometer method ASTM D 555006 (2000) was used. The representative value of $G_{s}$ was obtained from the average value of three tests as given as follows. Atterberg's limits such as liquid limit $\left(w_{l}\right)$, plastic limit $\left(w_{p}\right)$, plasticity index $\left(l_{p}\right)$, and shrinkage limit $\left(w_{s}\right)$ for the collected

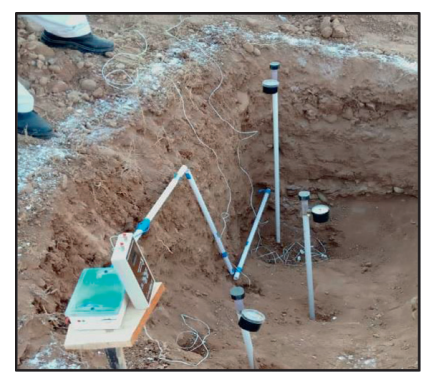

(a)

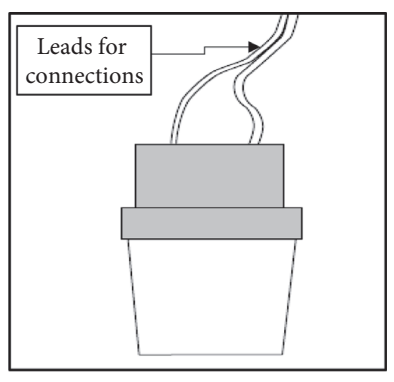

(b)
Figure 2: (a) Actual instrumentation in the field. (b) Electrical resistivity sensor used.

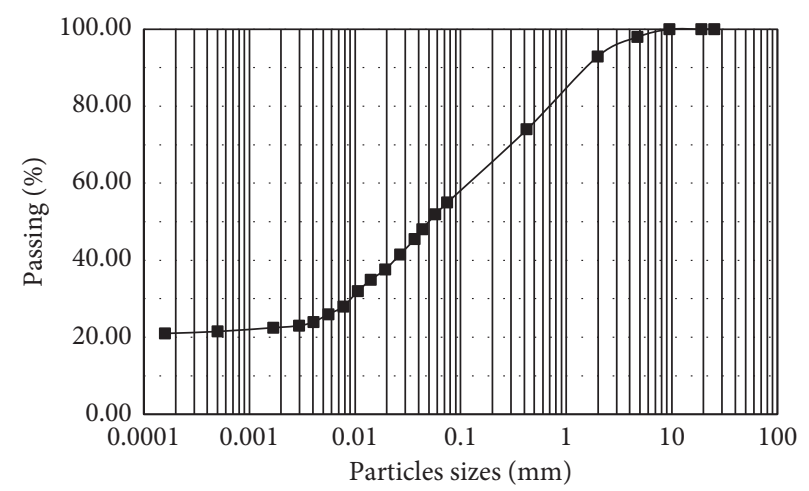

FIGURE 3: Grain size distribution curve of Karak expansive clay.

samples were determined according to the tests methodology ASTM D 4318-00 and ASTM D 427-04, respectively. For classification purposes, the unified soil classification system (USCS) was used. The designated group, based on the passing fraction percentage, $\left(w_{l}\right)$, and $\left(l_{p}\right)$, is listed in the table. All the collected samples from site A and site B having a plasticity index in the range of 23-45 belongs to the expansive soil of high expansion according to Gibbs and Holtz criteria [19]. Similarly, the samples from site $\mathrm{C}$ have a plasticity index in the range of 12-23 and hence are placed in medium expansive soils. The respective positions (average) of investigated soils were also plotted on the plasticity charts as shown in Figure 4. All the collected samples lie above the A-line showing the inorganic nature of these soils.

3.2. Free Swell Index (FSI). This simple test consists of taking 10 grams of oven-dried soil passing over sieve no. 40 (425 microns) in a $100 \mathrm{ml}$ graduated glass cylinder. In early time, Holtz and Gibbs proposed this method, and later on, it was standardized under the guidelines provided by IS (Indian Standard): 2911 Part III (1980). This test consists of observing the difference in volumes of an expansive soil wetted in two different liquids: Kerosene (nonpolar liquid) and a dipolar liquid (water). Oven-dried soil is poured into this liquid, followed by stirring the suspension, and placed on a horizontal platform allowing the soil to expand freely. After 24 hours of nondisturbed and stationary conditions, the increase in the height of soil is recorded. The volume of soil 
TABLe 1: Physical and swelling properties of the investigated soil.

\begin{tabular}{|c|c|c|c|c|c|c|c|c|c|c|}
\hline \multirow{2}{*}{ Sample designation } & \multirow{2}{*}{ Depths (ft) } & \multicolumn{4}{|c|}{ Physical properties } & \multicolumn{4}{|c|}{ Atterberg's limits (\%) } & \multirow{2}{*}{ USCS } \\
\hline & & $\gamma_{d \max } \mathrm{kN} / \mathrm{m}^{3}$ & OMC \% age & $G_{s}$ & FSI (\%) & $w_{l}$ & $w_{p}$ & $l_{p}$ & $w_{s}$ & \\
\hline \multirow{3}{*}{ Site A } & $0-2$ & 16.2 & 18.2 & 2.61 & 32.5 & 55 & 21 & 34 & 6 & \multirow{3}{*}{$\mathrm{CH}$} \\
\hline & $2-4$ & 17.6 & 17.5 & 2.62 & 33.3 & 52 & 18 & 34 & 8 & \\
\hline & $4-6$ & 18.0 & 19.0 & 2.60 & 34.0 & 60 & 22 & 38 & 10 & \\
\hline \multirow{3}{*}{ Site B } & $0-2$ & 17.0 & 16.0 & 2.64 & 32.4 & 58 & 19 & 39 & 10 & \multirow{3}{*}{$\mathrm{CH}$} \\
\hline & $2-4$ & 18.2 & 18.0 & 2.62 & 33.0 & 61 & 23 & 38 & 13 & \\
\hline & $4-6$ & 19.0 & 15.8 & 2.62 & 32.8 & 59 & 22 & 38 & 12 & \\
\hline \multirow{3}{*}{ Site C } & $0-2$ & 16.0 & 17.8 & 2.59 & 29.0 & 47 & 25 & 22 & 8 & \multirow{3}{*}{$\mathrm{CL}$} \\
\hline & $2-4$ & 17.5 & 19.0 & 2.58 & 28.5 & 45 & 22 & 23 & 8.5 & \\
\hline & $4-6$ & 18.3 & 16.4 & 2.63 & 29.5 & 44 & 22 & 22 & 9 & \\
\hline
\end{tabular}

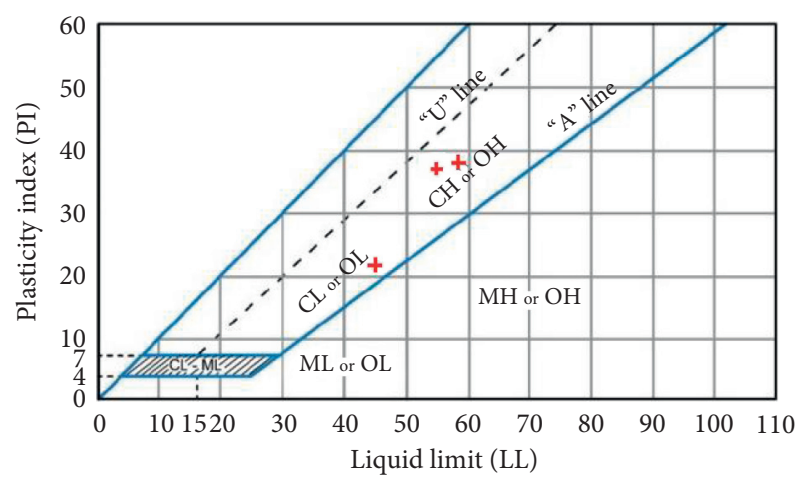

Figure 4: Place of Karak expansive soil on the plasticity chart (average values).

in water, " $V_{w}$," and kerosene " $V_{k}$ " is obtained by multiplying the height of soil with a cross-sectional area of the glass cylinders $[20,21]$. The arrangement made for the free swell test is mentioned in Figure 5(a). The free swell index, FSI (percentage), was obtained with the help of the following, and the results are listed in Table 1:

$$
\mathrm{FSI}=\frac{V_{w}-V_{k}}{V_{K}} \times 100,
$$

where $V_{w}$ and $V_{k}$ are the volumes of soil in water and kerosene oil, respectively.

3.3. XRD Analysis. Expansive clay minerals and particles are extremely small. There are thousands of different minerals present in a few grams of finally divide power form of clayey soil. Estimating the relative proportions of all clay minerals present in a representative sample using X-ray diffraction (XRD) is extremely difficult. However, the minerals that are present abundantly can be identified. The quantity and quality of each mineral impart certain physical and chemical behavior to the soil. Expansive clay owes some special characteristics due to the presence of clay minerals that belong to the smectite group. The most common type of smectite characterized by its expansion properties is montmorillonite. The term clay mineral is referred to as is referred to hydrous aluminum phyllosilicates minerals that are fine-grained $(<0.002 \mathrm{~mm})$ with sheet-like structure and

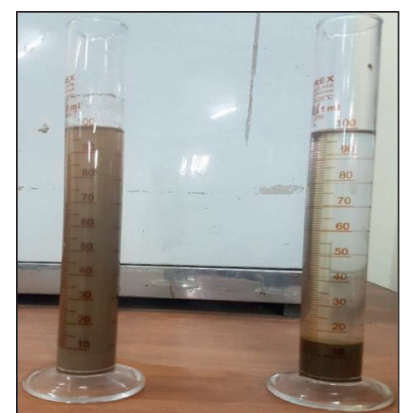

(a)

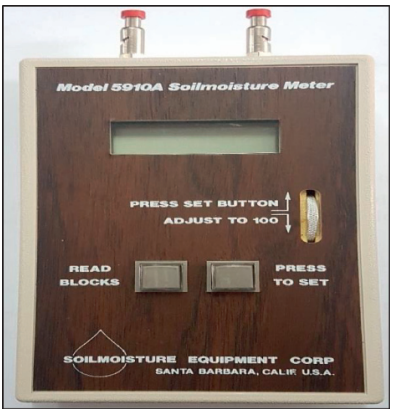

(b)

FIgURE 5: (a) Free swell index arrangement. (b) Moisture meter used for soil suction.

very high specific surface area [22]. The X-ray diffraction method is generally used for assessing the mineralogy, crystalline structures, and the atomic spacing of minerals. A cathode-ray tube is used for generating, concentrating, and directing the monochromatic radiation towards the samples [23]. In this method, the two components of radiation were $k \alpha$ and $k \beta$ while the wavelength of radiations was $1.54 \mathrm{~A}^{\circ}$.

The powder form of Karak's expansive soil was tested in the Central Research Lab (CRL) at the University of Peshawar. The raw data was then analyzed in MATCH 3.8 software and the complete diffraction pattern obtained is shown in Figure 6.

While performing qualitative analysis for the selected minerals, the sample showed various percentages of kaolinite and illite minerals showing the clayey nature of the soil. Some nonclayey like quartz and calcite minerals were also 


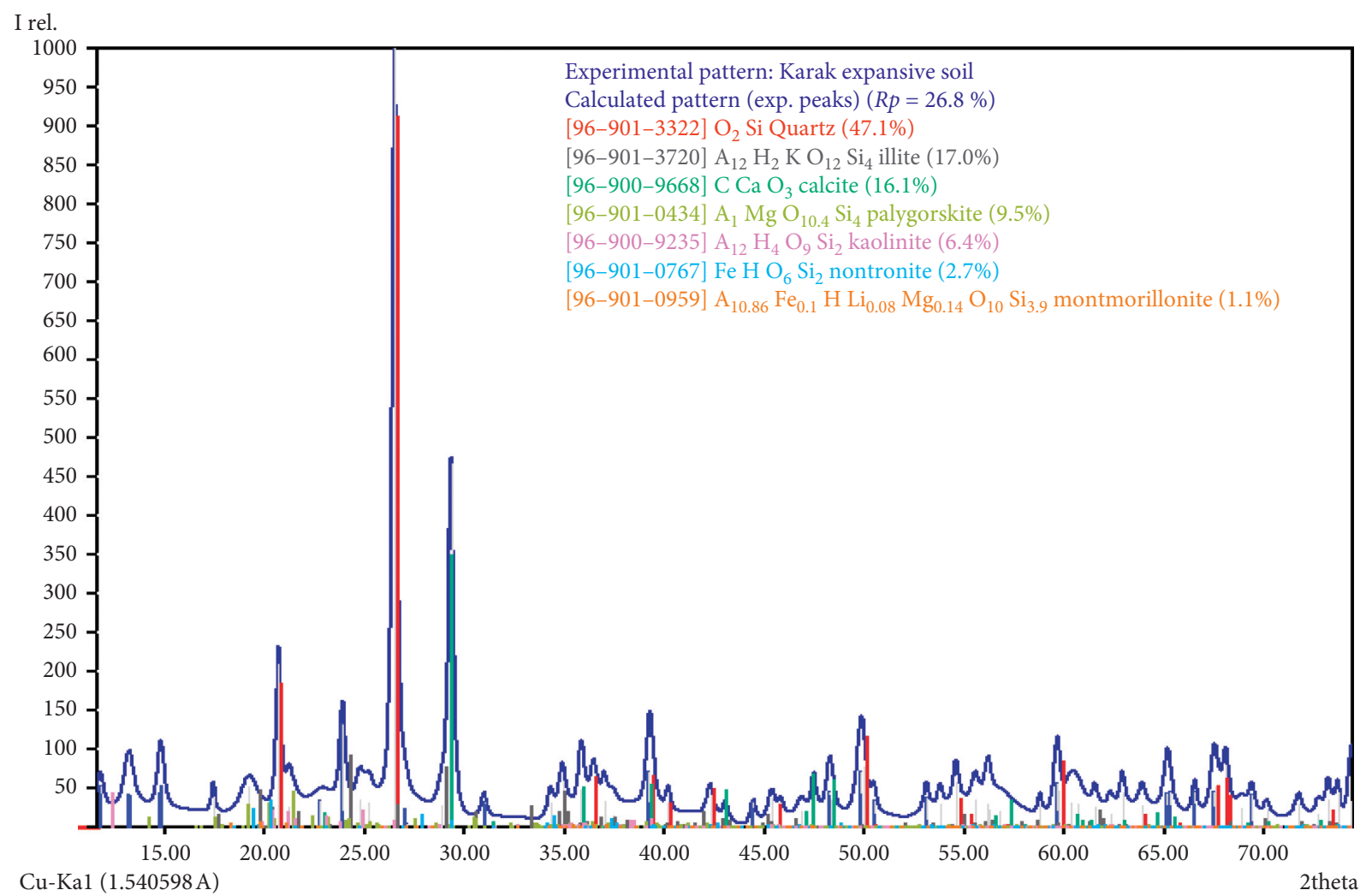

FIGURE 6: X-ray diffractogram of Karak expansive soil produced in MATCH.

found. The quantity of identified minerals as shown in Figure 5 is based on the selected minerals with a specific chemical formula and did not show the overall percentage of a mineral with different chemistry. The percentages of quartz, illite, calcite, palygorskite, kaolinite, nontronite, and montmorillonite were $47.10 \%, 17.0 \%, 16.10 \%, 6.40 \% 2.70 \%$, and $1.10 \%$, respectively, for the respective (mentioned) chemical compositions.

In this analysis, five types of montmorillonite with different chemical composition and percentages were found. The overall percentage of these montmorillonites was 8.9 percent as shown. Similarly, the percentage of nontronite, as calculated, is $6.4 \%$ with a triclinic structure. The individual diffractogram of some common minerals identified in XRD analysis is shown in Figure 7. The crystal system of both quartz and calcite was the same (trigonal and hexagonal axes). The quartz and calcite content revealed by XRD accounts for silt size fraction observed in the grain size distribution. Karak soil contains an enormous amount (20\%) of palygorskite (attapulgite) that is nondispersive. Palygorskite is a synonymous term for the same hydrated $\mathrm{Mg}$-Al silicate material. Unlike smectite, the palygorskite has special property of gel formation. The individual diffractogram indicated the presence of the montmorillonite and nontronite crystal system belonging to the smectite group in this soil. The minerals montmorillonite and nontronite are the two important smectites responsible for large cation exchange capacity (CEC) in the soil. Most of the shrinkage and swelling that occur in expansive soil are due to the presence of expandable smectite minerals. Smectite absorbs a large amount of water, which reduces the strength of the soil and triggers landslides and soil creep. On the other hand, these minerals have adhesive properties, which reduce soil erosion. The peak intensity belonging to the selected phase was $64.54 \%$ while the unidentified peak intensity was $35.46 \%$ as given by MATCH report.

3.4. SEM Characterization. A scanning electron microscope (SEM) technique was used to evaluate the surface images (morphology) of the specimen. SEM images at different magnification levels are shown above. Soil particle showed large flat layers of clay. These layers have the tendency of expansion upon the saturation. Due to simple disturbance, proper booklet and fiber-like structure are not seen in the images. The morphology of Karak expansive soil shows irregular agglomerates constituted by relatively flat sheets overlapped over each other as highlighted in Figure 8(a). Similarly, SEM images also showed abundantly the presence of fiber-like palygorskite minerals that were present in this expansive soil as evidenced in Figure 8(b), as these minerals are nondispersive and contribute to swelling and shrinkage of Karak's expansive soil.

\section{Field Instrumentation}

4.1. Electrical Conductivity Sensors. The electrical conductivity sensor consists of a porous block and two concentric electrodes embedded inside the block. The porous block 


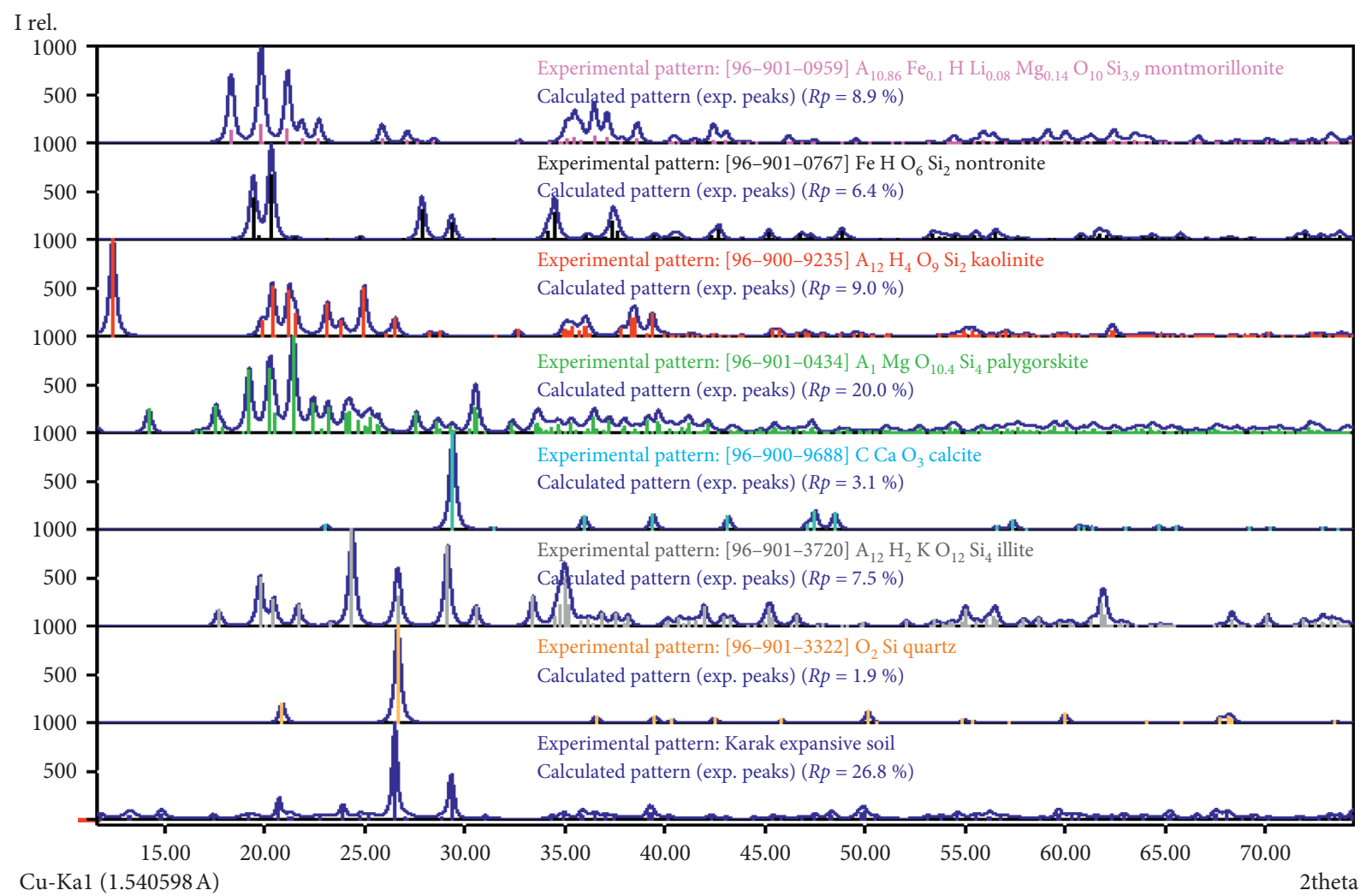

FIGURE 7: Diffractogram showing the intensity of selected minerals.

serves the same purpose as the porous block in the thermal conductivity sensor. However, instead of thermal conductivity, the electrical conductivity sensor measures the electrical conductivity of the porous block. Electrical conductivity sensors are commercially available manufactured by different companies (e.g., Soil moisture Inc., Measurement Engineering Australia, Delmhorst Instrument Company, Irrometer Company Inc., and Environmental Sensors Inc.) [24].

Electrical conductivity sensors in the form of blocks (gypsum) have been used in field instrumentation for calculating the in situ suction. Soil suction is measured in terms of the water potential of the porous blocks, which are related to the electrical response of the sensors embedded in these blocks. The water content of these blocks is correlated with suction curves usually provided by the manufacturer. Due to the low cost, easy availability, and advancement in this technology of the porous block, they are getting popularity in the field of unsaturated soil mechanics for high suction range (up to $100000 \mathrm{kPa}$ ).

Gypsum blocks (G-blocks) are the most cost-effective method for measuring matric potential by electronic means. These blocks have been designed to provide a large range of matric suction. The sensitivity of the electrode ensures responding to the moisture condition below $2 \mathrm{kPa}$ of matric suction with an overall range of $1000 \mathrm{kPa}$. In the current research, 5201F SERIES gypsum block (Figure 8(b)) for soil suction along with 5910-A moisture meter (Figure 5(b)) manufactured by soil moisture equipment corporation (USA) was used. The Model 5201F Gypsum Blocks feature a slim $(2.20 \mathrm{~cm})$ diameter and have a life span of 2-4 years. Among the all-porous blocks used for matric suction measurements, the gypsum block sensor is very suitable owing to the shortest time of saturation and quick response to soil suction [25]. Gypsum blocks have the characteristic of buffering the soil salinity, thereby reducing the effect of dissolved salts on the matric potential of soil [24].

The schematic installation of sensors for field monitoring is shown in Figure 2(a). Three G-blocks sensors were installed at different depths along with a moisture sensor for measuring high suction (up to $1000 \mathrm{kPa}$ ) and gravimetric moisture content. Moisture sensors were first installed in the excavated trench for finding the natural moisture content and then placed with the G-blocks sensors for the induced moisture content. Similarly, three tensiometers were also installed parallel to the sensors at the same depth for measuring low suction $(100 \mathrm{kPa})$. The tensiometer used in this study was provided by the Water Resources Research Center (WRRC), Peshawar. These tensiometers have the capacity of measuring the suction up to $100 \mathrm{kPa}$ ( 1 bar).

The variation of low and high suction was taken from the tensiometers and readout unit of the gypsum block sensors, respectively. After taking the reading at an interval rate of maximum of 30 minutes for seven consecutive days in each site, the suction curves were then plotted concerning time and gravimetric moisture content. To determine the suction from meter reading, the following governing equation was 

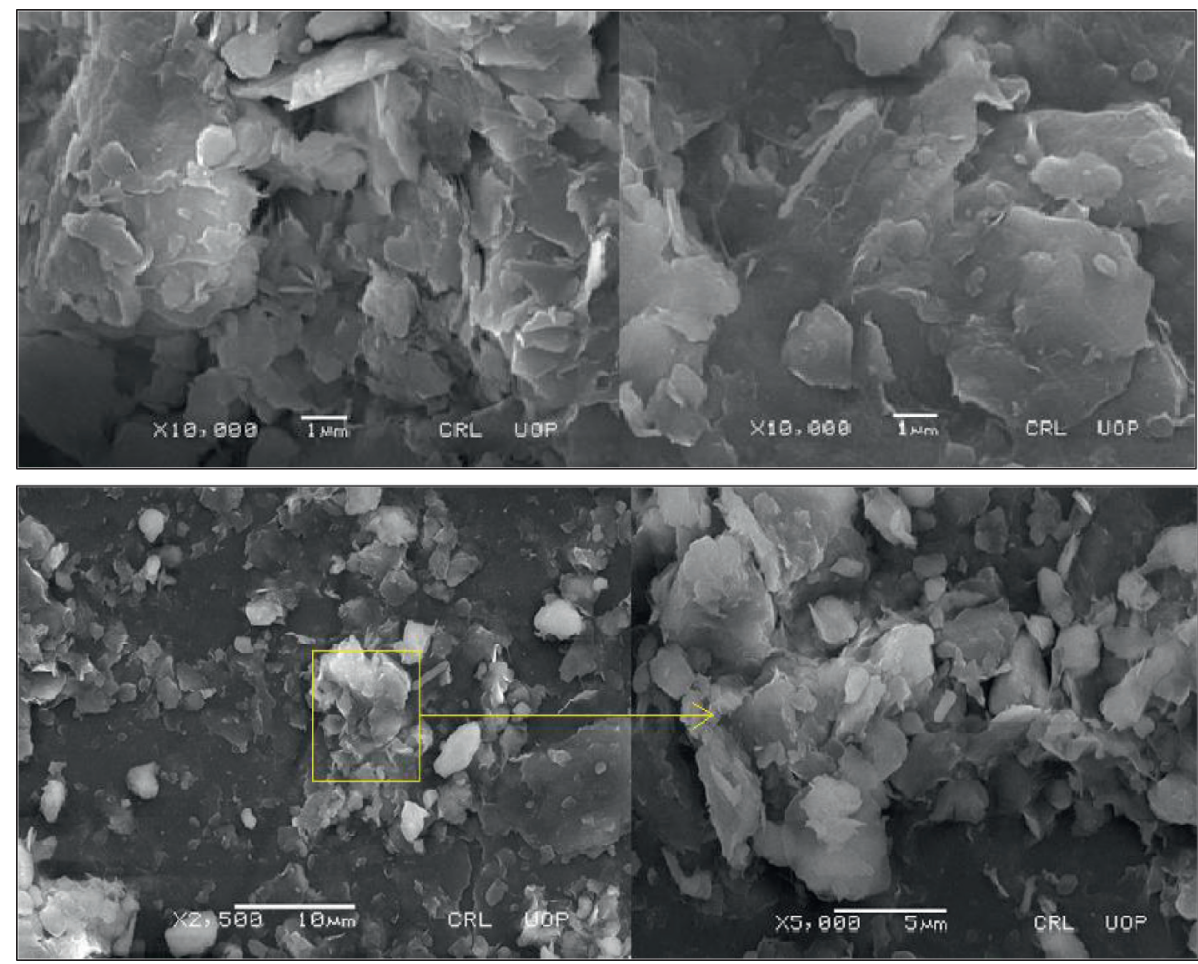

(a)

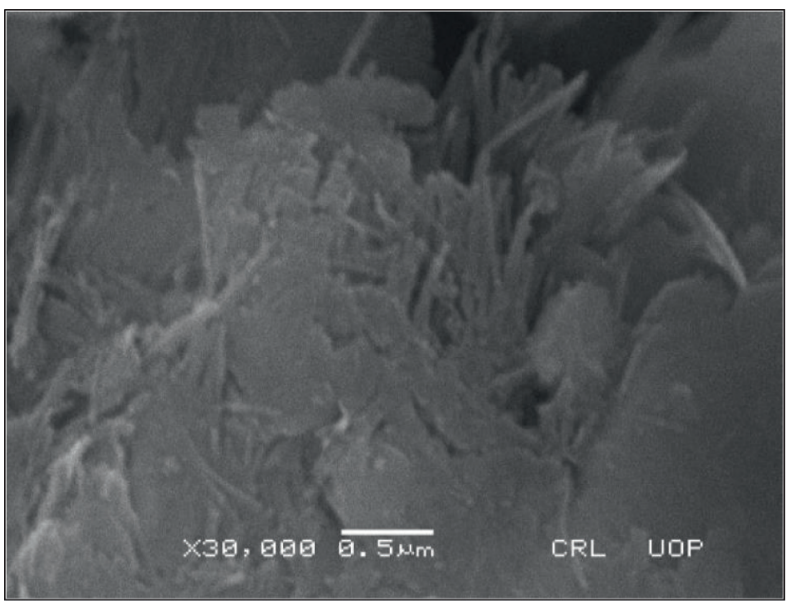

(b)

FIGURE 8: (a) SEM images of expansive soil at a different magnification level. (b) SEM image showing the fiber-like structure of palygorskite.

used as given by Soilmoisture Equipment Corporation for G-blocks sensors with moisture meter readings $(x)$ :

$$
\text { soil suction }(\mathrm{kPa})=\left[\frac{\left(a+c x+e x^{2}+g x^{3}\right)}{\left(1+b x+d x^{2}+f x^{3}\right)}\right] x 100 \text {. }
$$

Values needed for Formula functions are $a=13.138406$, $b=-0.0060118606, c=-2.0634819, d=0.12530109, e=$ $0.36983843, f=0.0046851706$ and $g=-0.0035353683$,

4.2. Moisture Sensors. The low-cost moisture sensors were calibrated with speedy moisture equipment for 100\% (saturation) and $0 \%$ (dried) moisture content of the expansive soil collected from the tranches for the subsequent use of in situ moisture content. The accuracy of these sensors was $\pm 2 \%$ as given by the manufacturer. These sensors were connected with a data logger (Arduino-based module) for sensing moisture content for the specified time interval and storing the data in the field. The module used here was programmed in the IDE (Integrated Development Environment) as shown in Figure 9.

4.3. Soil-Water Characteristic Curve (SWCC). The soil-water characteristic curve (SWCC) refers to the amount of water present inside the soil pores for a given suction level. As the amount of water present in the soil can be expressed in the 


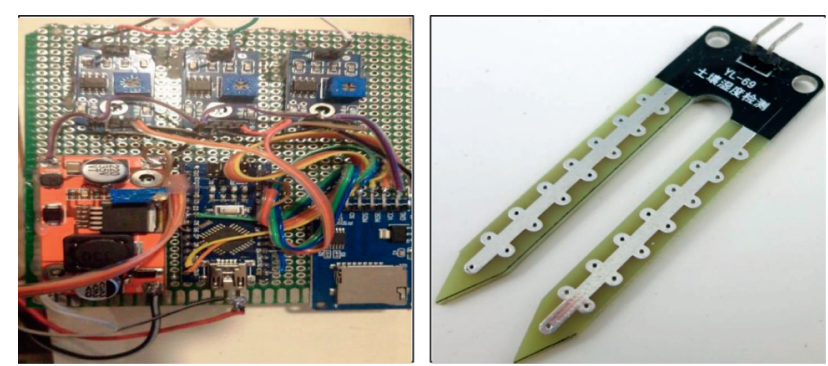

Figure 9: Moisture sensors and data logger for gravimetric moisture content measurement.

form of gravimetric water content, volumetric water content, and degree of saturation, so the SWCCs may be established using either form of the moisture. The main difference between these three forms of the SWCC is the consideration of the soil volume change during changes in soil suction. If the volume changes are not considered, then the fitting parameters for all the three forms of SWCC will be the same [26]. These fitting parameters are required for deriving and studying many fundamental properties of unsaturated soils, that is, hydraulic conductivity $[27,28]$, shear strength $[29,30]$, and coefficient of diffusion and adsorption [31].

The soil-water characteristic curve (SWCC) defines the constitutive relationship between the soil-water potential and moisture content of unsaturated soils, which may be utilized to bridge the gap between the saturated and unsaturated soil [32]. The density or porosity of soil can change considerably, depending on the stress and suction states as well as the stress and suction history of the soil. On the other hand, the SWCCs are characterized for a given soil only at a specific density and specific stress level. Change of soil density can lead to a significant change of the SWCC, and such a change in soil density is a common feature of natural soils [33].

SWCC is an important tool to be determined while using unsaturated soil mechanics in engineering practice. The technologies regarding the SWCC were originally developed in soil physics and agriculture-related disciplines. These technologies have gradually been embraced, with some modifications, in the application of unsaturated soil mechanics [33]. Like the laboratory techniques mentioned previously, several techniques have been utilized for assessing the soil matric suction $(\psi)$ and volumetric moisture content $(\theta v)$ of soil in the field (in situ), and these parameters can be used to determine SWCC and $\mathrm{k}$-functions. The time-domain reflectometry technique has been used for calculating volumetric water contents. Similarly, the TDR sensors were also presented in various literature [34]. Tensiometers can be used for accurate measurements of matric potential because of the direct measurement of soil suction [35]. Field supervision for SWCCs chiefly involves the measurement of the soil suction and moisture content (in situ). In measuring these two variables in the field, it is possible to confirm that the in situ SWCCs are in reasonable correspondence with the design curves parameters [36].

\section{Results and Discussion}

Test results for the adopted methodology of matric suction are presented here. The time and suction relation for all the sites showed that, with an increase in the time, the suction for a given expansive soil increased due to the absorption of moisture by lower layers. Hence, the actual matric suction is the time-dependent property of the soil. Comparatively more time is required by expansive soil for complete drying. At the start, the increase in soil suction was quite low due to the high concentration of water around the gypsum blocks and moisture sensors. After 40-, 45-, and 20-hour elapse of time for site $A$, site $B$, and site $C$, respectively, the drying process of moisture occurred as clear from Figures 10-12. The drying process of sites $\mathrm{A}$ and $\mathrm{B}$ was quicker than site $\mathrm{C}$ due to the low plasticity (CL) nature of site C. The suctions measured with tensiometers were close enough up to a certain extent with the sensors installed in the upper layers for all the sites.

Tensiometers were also installed parallel to the moisture and suction sensors for the purpose to find the fluctuation of low matric suction at the same depth as that of the sensors. The suction values obtained from all three tensiometers for all the depths were the same for each site and their average values are shown in the upcoming figures. The response of all the tensiometers up to suction of $30 \mathrm{kPa}$ was about 8 hours after the installation. Beyond that suction, the measured suctions were close to the suctions measured by electrical resistivity sensors in the top layer ( $0-2$ feet). Higher suction could not be compared due to the limitation of tensiometers.

Due to the drying of moisture around the sensors, a rapid increase in the soil suction was absorbed, as expansive soil contains montmorillonite, having a high absorption capacity of water molecules between its sheets. This property is responsible for keeping expansive soil in an unsaturated condition and their voids were partly filled with water and air before the water uptake. During the water absorption, montmorillonite layers expand and fill the available voids in the soil. After filling these voids, the movement of water due to gravity in the lower layers is reduced due to blockage of the flow path. Due to this unique behavior of expansive soil, the time for the full development of suction was very prolonged, that is, 146.5 hours. It may be more prolonged for the suction up to the complete dry conditions.

The typical SWCCs for site A, site B, and site C are shown in Figures 13-15, as suction and moisture content were measured at different depths in the field. Due to the difference in the overburden pressure at each point, the fieldobtained SWCCs vary at various depths. Similarly, the variations of in situ density and void ratio along the depths were also responsible for the different SWCCs. The maximum suction was $705 \mathrm{kPa}$ at the depth (0-2 feet) near the 


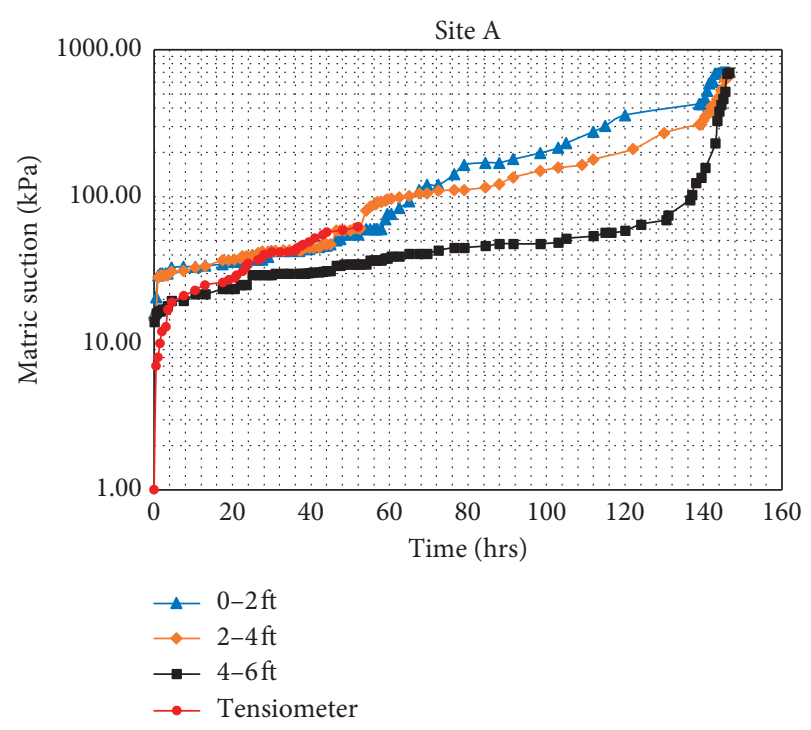

FIgURE 10: Typical curves showing the variation of suction with time for site A.

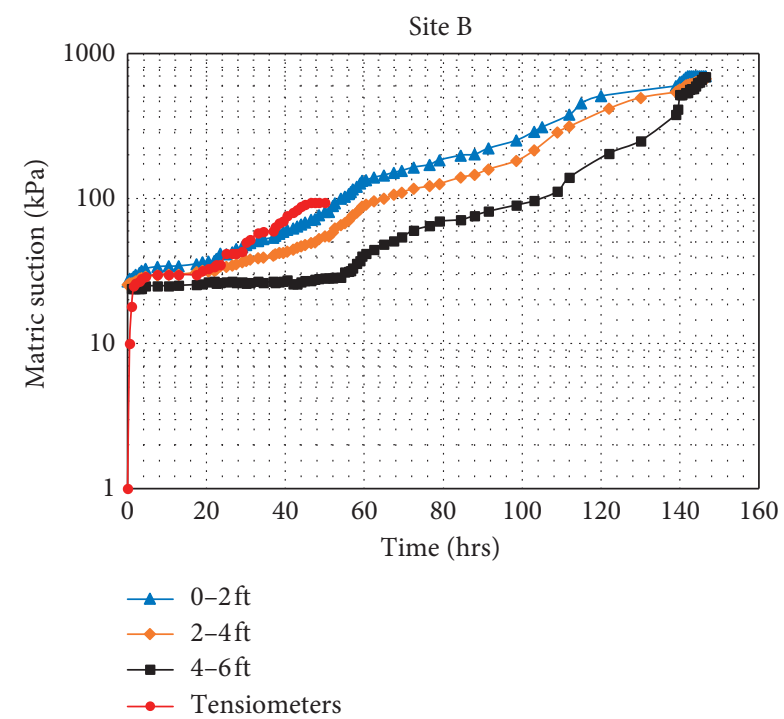

Figure 11: Typical curves showing the variation of suction with time for site B.

surface with a moisture content of $15 \%$. The initial moisture content in all the sites was in the range of $60-64 \%$. Over time, the moisture content reduced, increasing the matric suction. The maximum and minimum value of suction in lower depths were close to the top layer suctions although their rate was quite slow compared to the top depth at a constant interval of time. Moreover, it is observed that high moisture content values were maintained by lower depth (0-6 feet) for the same suction as that of upper layers.

After wetting depth, the increase in the matric suction was quite pronounced. The rate of change of soil suction with gravimetric moisture content was different for all the three sites but the peak values achieved were approximately

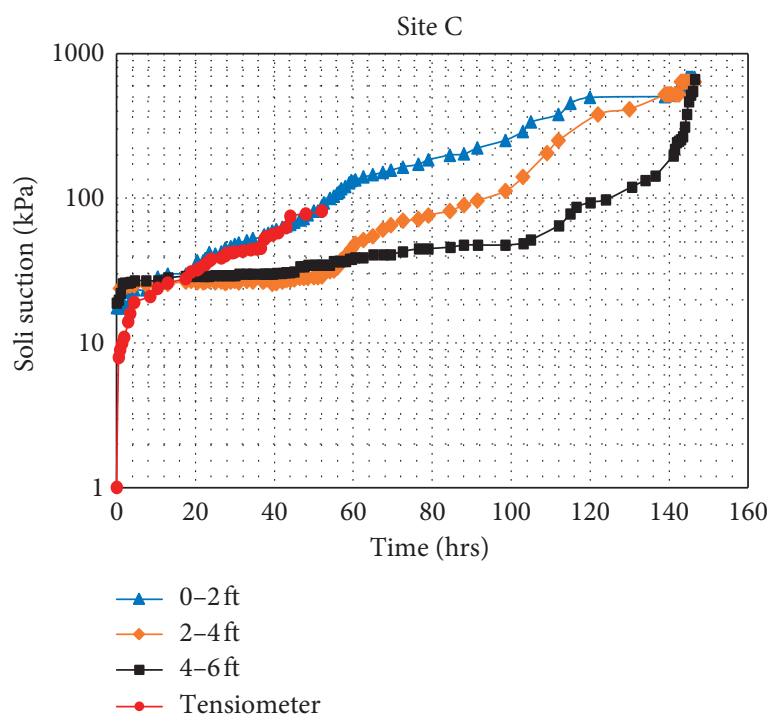

FIGURE 12: Matric suction relation concerning time for site C.

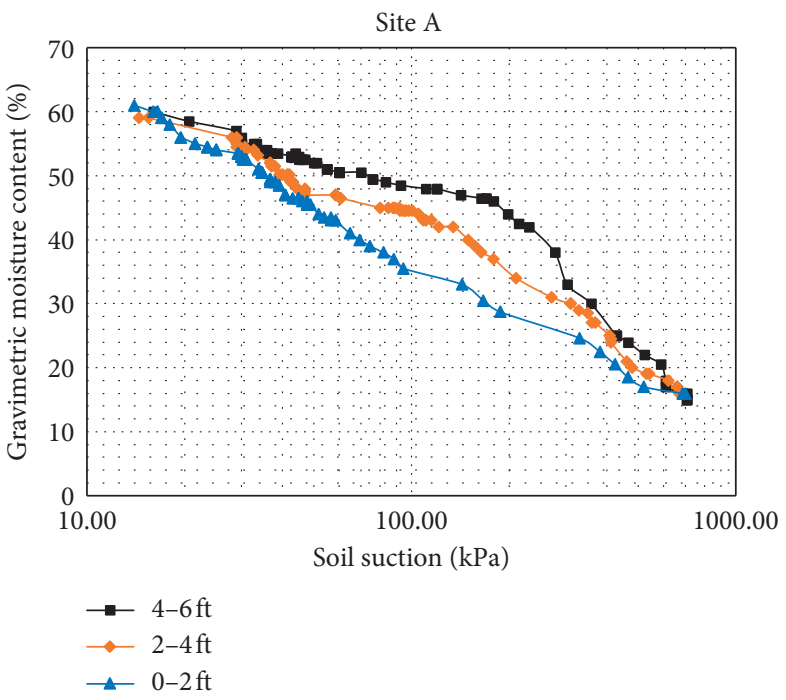

FIgure 13: Typical soil-water characteristic curves for site A.

the same for all the depths. It was noted that the matric suctions in the top layers were higher than the middle and lower layers at the same time interval in all the sites as clear from figures. Conversely, higher moisture content was maintained by lower layers than the upper layers at the same values of matric suctions.

As expansive soil is residual in nature and their composition and mineralogy remain constant specifically in shallow depth that is the main reason behind the close vales of peak suctions, conversely, the fluctuation of suction concerning time and moisture is due to their different exposure to environmental effects. Environmental agencies like humidity in the air, ambient temperature, and the direction and velocity of the wind in the sites have an influential effect on the matric suction (not considered here). 


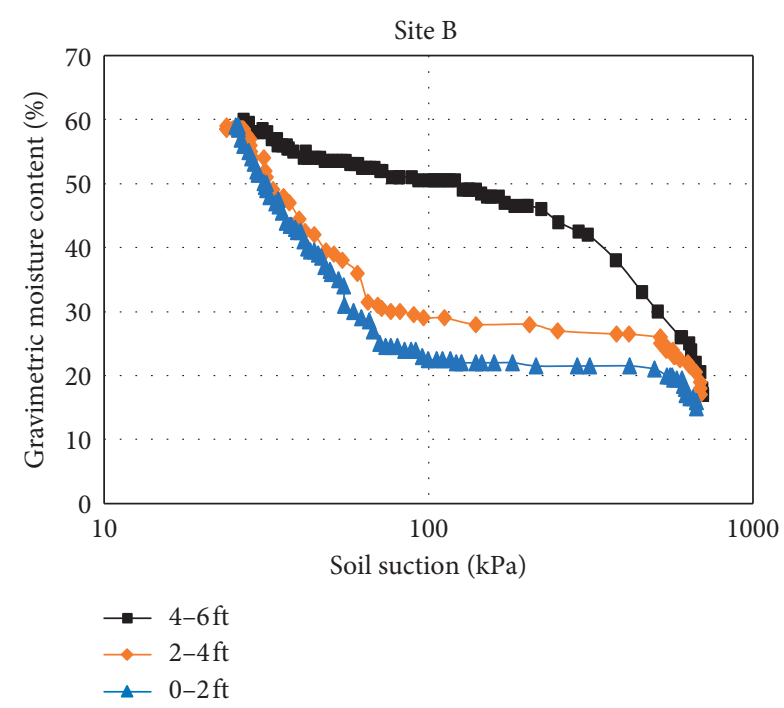

FIgURE 14: Soil-water characteristic curves (SWCC) for site B.

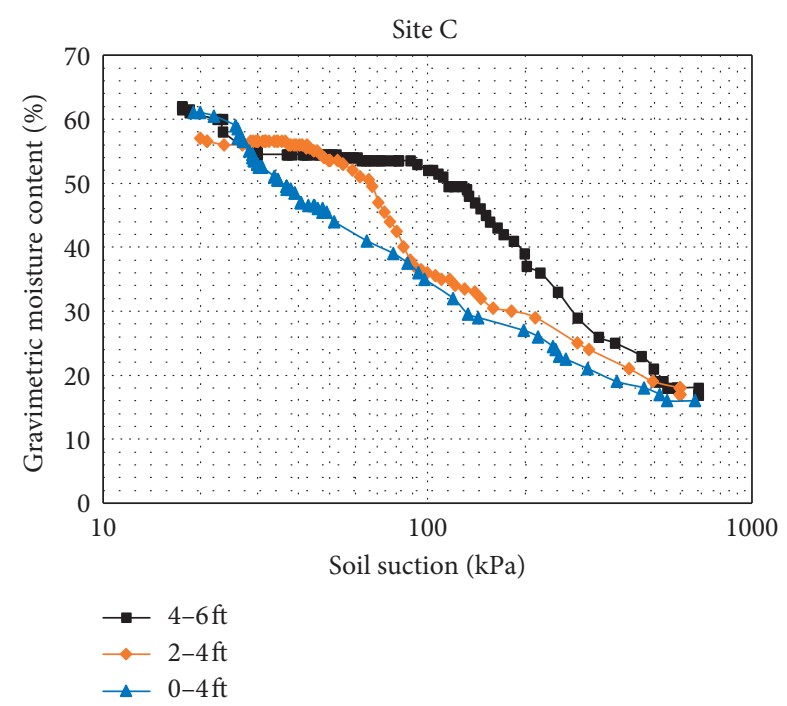

Figure 15: Soil-water characteristic curves (SWCC) for site C.

Similarly, the suction measured at the site can be changed for a given expansive soil due to changes in the stress condition, consolidation, permeability, and voids ratio at different depths.

\section{Correlation Development in Statistical Package (SPSS)}

For managing the obtained data and developing correlations, statistical package SPSS (Statistical Package for Social Sciences) version 22 was used. The input parameters for regression analysis in SPSS were moisture content $(\omega)$, matric suction $(\Psi)$, and free swell index (FSI). For correlation, development among these variables the following three methods of analysis was carried out.
TABLe 2: Coefficient generated by IBM SPSS.

\begin{tabular}{|c|c|c|c|c|c|}
\hline \multirow{2}{*}{ Model } & \multicolumn{2}{|c|}{$\begin{array}{l}\text { Unstandardized } \\
\text { coefficients }\end{array}$} & \multirow{2}{*}{$\begin{array}{c}\text { Standardized } \\
\text { coefficients } \\
\text { Beta }\end{array}$} & & \multirow{2}{*}{ Sig. } \\
\hline & B & $\begin{array}{l}\text { Std. } \\
\text { error }\end{array}$ & & & \\
\hline Constant & 1058.776 & 130.01 & & 8.144 & 0.00 \\
\hline$\omega$ & -14.853 & 0.481 & -0.924 & -30.879 & 0.00 \\
\hline FSI & -9.744 & 6.065 & -0.048 & -1.607 & 0.11 \\
\hline
\end{tabular}

TABle 3: Model summary and parameter estimates for linear regression.

\begin{tabular}{lcccccccc}
\hline \multirow{2}{*}{ Equation } & \multicolumn{4}{c}{ Model summary } & \multicolumn{3}{c}{$\begin{array}{c}\text { Parameter } \\
\text { estimates }\end{array}$} \\
& $R^{2}$ & $F$ & $d f 1$ & $d f 2$ & Sig. & Constant & $b 1$ \\
\hline Linear & 0.882 & 3655.426 & 1 & 490 & 0 & 800.035 & -14.508 \\
\hline
\end{tabular}

6.1. Correlation between Moisture Content, Suction, and FSI. The total input data points were 765 (85readings $\times$ 3 depth $\times 3$ sites) for moisture and suction obtained from sensors, while 24 free swell tests were performed on the disturbed samples in the laboratory. For developing a correlation between moisture content, suction, and free swell index, the bivariate analysis method was used. The generated report by SPSS is shown in Table 2. Based on the estimated coefficient, the correlation equation has been developed in equation (3). This equation shows that moisture content $(\omega)$ is highly significant while the free swell index has the least significance with the soil suction:

$$
\Psi=1058.776-14.853 \omega-9.744 \text { FSI. }
$$

6.2. Linear Regression Analysis. Analysis based on linear regression was performed on the same data as that for equation (3). This analysis was based on the soil suction (dependent variable) and moisture content (independent variable). This analysis gives a regression equation with $R^{2}=0.882$, which is more accurate and required only one parameter for estimating the soil suction (Table 3 ). The details for this analysis are shown in Table 4. The significance level is 0.000 (high), showing a strong contribution of moisture content with soil suction:

$$
S c=800.035-14.508 \omega \text {. }
$$

$$
\Psi=1313.662-47.383 \omega-0.440 \omega^{2} .
$$

6.3. Quadratic Regression. The quadratic regression analysis was also carried out based on two variables, that is, soil suction, a dependent variable, and moisture content, an independent variable. The prediction equation for quadratic analysis is shown in equation (5). The $R^{2}$ value was 0.957 , 
TABLE 4: Model summary and parameter estimates for quadratic regression.

\begin{tabular}{lcccccccc}
\hline \multirow{2}{*}{ Equation } & \multicolumn{4}{c}{ Model summary } & \multicolumn{3}{c}{ Parameter estimates } \\
& $R^{2}$ & $F$ & $d f 1$ & $d f 2$ & Sig. & Constant & $b 1$ & $b 2$ \\
\hline Quadratic & 0.957 & 5446.51 & 2 & 489 & 0 & 1313.662 & -47.383 \\
\hline
\end{tabular}
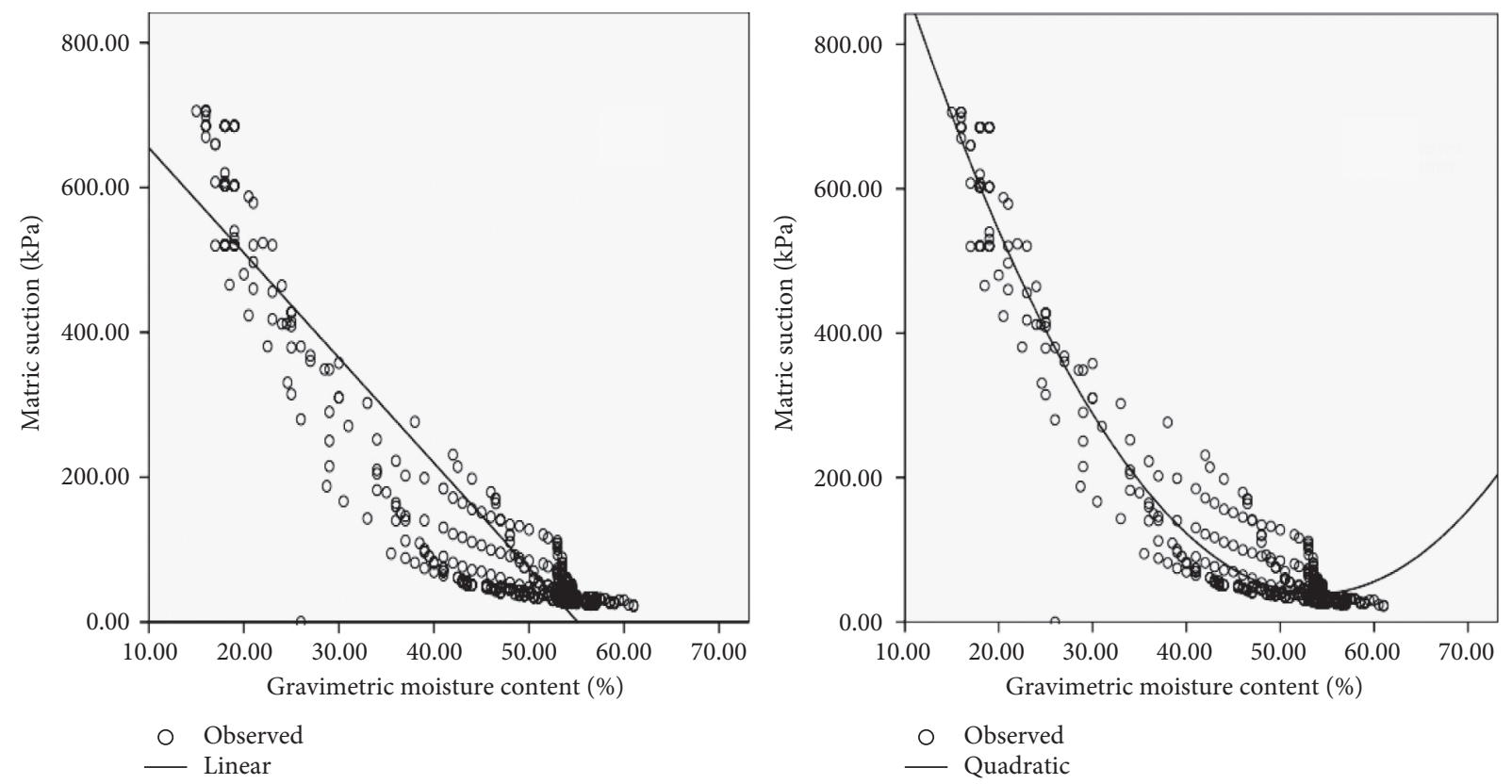

FIGURE 16: Line graphs produced in SPSS for linear and quadratic analysis.

showing a high significance level for this correlation. Table 4 shows the details of the estimated equation, degree of freedom, and regression values.

Figure 16 shows the line graphs for linear and quadratic analysis. The quadratic equation is more precise and appropriate for predicting the soil suction from the measured water content.

\section{Conclusions and Recommendations}

A study has been undertaken to assess the in situ SWCCs for the local expansive soil deposits in Pakistan. For this purpose, three sites of expansive soil were instrumented with moisture and suction measuring devices. The following conclusions can be drawn from this study.

(i) The Karak expansive soil consists of minerals belonging to the smectite group of clay. The major reason for the expansion and contraction of these soils is the presence of montmorillonite, nontronite, and palygorskite minerals. Most of the soils in the selected site belong to high expansive soil except site C.

(ii) Different SWCCs were obtained from all sites as well as from different depths because of the hysteretic nature of SWCCSs and different physical conditions. If the same soil is assessed in the laboratory for their wetting and drying curves than the field, data will possibly be placed within the hysteretic loop of SWCCs.

(iii) The difference in the field and laboratory SWCCs is mainly due to the confinement conditions. In the laboratory, the soil samples are completely confined in a rigid container, while in the field, the soil is confined by shallow layers of soil. Under complete confinement, laboratory SWCCs show comparatively low suction for the same moisture content than the field SWCCs as evident from the previous study.

(iv) The obtained SWCCs were based on the data collected during the dry session for a short period. Some fluctuation could be seen in field SWCCs if the data is collected in other sessions.

(v) Soil suction measured with tensiometers was close enough at low suction range with the G-blocks sensors. Due to the limitation of tensiometers, high suction values cannot be compared with the suction measured with G-blocks sensors.

(vi) The prediction equation developed here can be used by practicing engineers for determining the approximate values of the suction in the field. The consideration of these suction characteristics in pavement design assists in selecting favorable 
engineering properties, such as resilient modulus, shear strength, compressibility, and hydraulic conductivity.

(vii) The prediction equation presented here can be used for calculating the approximate values of suction in the field by knowing the moisture content and free swell index.

(viii) The prediction correlation is based on the actual field data obtained from field instrumentation. Out of the above three equations, the quadratic equation is more precise and appropriate than the linear regression equation due to $R^{2}=0.957$ very close to the one.

(ix) However, due to the difference in the soil density, voids ratio, stress history, and permeability in the field, the predicted equations have limited applications while using for soils other than expansive soils.

(x) It is recommended here that more experimental work is required in this area for further refinement and also environmental effect must be countered for precise and accurate measurement of matric suction.

\section{Data Availability}

The background data used for supporting the findings of this research work are available from the corresponding author upon request.

\section{Conflicts of Interest}

The authors of this research article have no conflicts of interest regarding its publication.

\section{References}

[1] E. Ene and C. Okagbue, "Some basic geotechnical properties of expansive soil modified using pyroclastic dust," Engineering Geology, vol. 107, no. 1-2, pp. 61-65, 2009.

[2] D. G. Fredlund, "Unsaturated soil mechanics in engineering practice," Journal of Geotechnical and Geoenvironmental Engineering, vol. 132, no. 3, pp. 286-321, 2006.

[3] J. Nelson and D. J. Miller, Expansive Soils: Problems and Practice in Foundation and Pavement Engineering, John Wiley \& Sons, Hoboken, NJ, USA, 1997.

[4] C. W. W. Ng, L. T. Zhan, C. G. Bao, D. G. Fredlund, and Bi W. Gong, "Performance of an unsaturated expansive soil slope subjected to artificial rainfall infiltration," Geotechnique, vol. 53, no. 2, pp. 143-157, 2003.

[5] L. Zhan, "Field and laboratory study of an unsaturated expansive soil associated with rain-induced slope instability," Hong Kong University of Science and Technology, Hong Kong, China, Ph.D civil engineering, 2003.

[6] S. Uzundurukan, S. N. Keskin, S. N. Keskin et al., "Suction and swell characteristics of compacted clayey soils," Arabian Journal for Science and Engineering, vol. 39, no. 2, pp. 747752,2014
[7] V. K. S. Thakur and D. N. Singh, "Rapid determination of swelling pressure of clay minerals," Journal of Testing and Evaluation, vol. 33, no. 4, pp. 239-245, 2005.

[8] Y. Chen, B. Li, Y. Xu, Y. Zhao, and J. Xu, "Field study on the soil water characteristics of shallow layers on red clay slopes and its application in stability analysis," Arabian Journal for Science and Engineering, vol. 44, no. 5, pp. 5107-5116, 2019.

[9] J.-F. Liu, F. Skoczylas, and J. Liu, "Experimental research on water retention and gas permeability of compacted bentonite/ sand mixtures," Soils and Foundations, vol. 54, no. 5, pp. 1027-1038, 2014.

[10] D. K. Jensen, M. Tuller, L. W. de Jonge, E. Arthur, and P. Moldrup, "A new two-stage approach to predicting the soil water characteristic from saturation to oven-dryness," Journal of Hydrology, vol. 521, pp. 498-507, 2015.

[11] C. M. G. Blanco, V. M. B. Gomez, P. Crespo, and M. Ließ, "Spatial prediction of soil water retention in a Páramo landscape: methodological insight into machine learning using random forest," Geoderma, vol. 316, pp. 100-114, 2018.

[12] M. Bittelli and M. Flury, "Errors in water retention curves determined with pressure plates," Soil Science Society of America Journal, vol. 73, no. 5, pp. 1453-1460, 2009.

[13] P. Dobriyal, A. Qureshi, R. Badola, and S. A. Hussain, "A review of the methods available for estimating soil moisture and its implications for water resource management," Journal of Hydrology, vol. 458-459, pp. 110-117, 2012.

[14] L. Chow, Z. Xing, H. Rees, F. Meng, J. Monteith, and L. Stevens, "Field performance of nine soil water content sensors on a sandy loam soil in New Brunswick, Maritime region, Canada," Sensors, vol. 9, no. 11, pp. 9398-9413, 2009.

[15] A. V. F. A. Bertolino, A. P. Souza, N. F. Fernandes, A. M. Rangel, T. M. P. de Campos, and C. C. Shock, "Comparison of the soil matrix potential using tensiometers and watermark sensors," Oregon State University, Corvallis, OR, USA, 2002.

[16] W. H. Johnston, "Calibration of gypsum blocks and data loggers and their evaluation for monitoring soil water status," Australian Journal of Experimental Agriculture, vol. 40, no. 8, pp. 1131-1136, 2000.

[17] B. Krause, T. Villmow, R. Boldt, M. Mende, G. Petzold, and P. Pötschke, "Influence of dry grinding in a ball mill on the length of multiwalled carbon nanotubes and their dispersion and percolation behaviour in melt mixed polycarbonate composites," Composites Science and Technology, vol. 71, no. 8, pp. 1145-1153, 2011.

[18] A. Tang, L. Su, and C. Li, "Effect of dry grinding on the physicochemical properties of silica materials prepared from kaolin residue," Powder Technology, vol. 218, pp. 86-89, 2012.

[19] A. Sridharan and K. Prakash, "Classification procedures for expansive soils," Proceedings of the Institution of Civil Engineers-Geotechnical Engineering, vol. 143, no. 4, pp. 235-240, 2000.

[20] W. G. Holtz, "Engineering properties of expansive clays," Transactions of the American Society of Civil Engineers, vol. 121, pp. 641-677, 1954.

[21] A. Sridharan and P. Keshavamurthy, "Expansive soil characterization: an appraisal," Indian National Academy of Engineering, vol. 1, pp. 29-33, 2016.

[22] F. Uddin, "Clays, nanoclays, and montmorillonite minerals," Metallurgical and Materials Transactions A, vol. 39, no. 12, pp. 2804-2814, 2008.

[23] A. A. Bunaciu, E. g. Udriştioiu, and H. Y. Aboul-Enein, "X-ray diffraction: instrumentation and applications," Critical Reviews in Analytical Chemistry, vol. 45, no. 4, pp. 289-299, 2015. 
[24] R. Bulut and E. C. Leong, "Indirect measurement of suction," in Laboratory and Field Testing of Unsaturated Soils, pp. 2132, Springer, Dordrecht, Netherland, 2008.

[25] Hu Pan, Q. Yang, and Li Pei-yong, "Direct and indirect measurement of soil suction in the laboratory," Electronic Journal of Geotechnical Engineering, vol. 15, no. 3, pp. 1-14, 2010.

[26] Q. Zhai and H. Rahardjo, "Soil-water characteristic curve variables," in Proceedings of the Conference Paper, Proceeding of the International Symposium on Unsaturated Soil Mechanics and Deep Geological Waste Disposal, Shanghai, China, July 2013.

[27] Q. Zhai and H. Rahardjo, "Estimation of permeability function from the soil-water characteristic curve," Engineering Geology, vol. 199, pp. 148-156, 2015.

[28] J. Teng, X. Zhang, S. Zhang, C. Zhao, and D. Sheng, "An analytical model for evaporation from unsaturated soil," Computers and Geotechnics, vol. 108, pp. 107-116, 2019.

[29] J.-P. Wang, N. Hu, B. François, and P. Lambert, "Estimating water retention curves and strength properties of unsaturated sandy soils from basic soil gradation parameters," Water Resources Research, vol. 53, no. 7, pp. 6069-6088, 2017.

[30] J. Teng, F. Shan, Z. He, S. Zhang, G. Zhao, and D. Sheng, "Experimental study of ice accumulation in unsaturated clean sand," Géotechnique, vol. 69, no. 3, pp. 251-259, 2019.

[31] N. Lu, "Generalized soil water retention equation for adsorption and capillarity," Journal of Geotechnical \& Geoenvironmental Engineering, vol. 142, no. 10, 2016.

[32] D. G. Fredlund, H. Rahardjo, and M. D. Fredlund, Unsaturated Soil Mechanics in Engineering Practice, John Wiley \& Sons, Inc., Hoboken, NJ, USA, 2012.

[33] J. Zhou and Y. Jian-Lin, "Influences affecting the soil-water characteristic curve," Journal of Zhejiang University Science A, vol. 6, no. 8, pp. 797-804, 2005.

[34] C. D. Garner and R. A. Coffman, "Volumetric water content measurements as obtained from remote sensing and in situ instrumentation," Journal of Environmental and Engineering Geophysics, vol. 21, no. 4, pp. 151-160, 2016.

[35] W. R. Whalley, G. Lock, M. Jenkins et al., "Measurement of low matric potentials with porous matrix sensors and waterfilled tensiometers," Soil Science Society of America Journal, vol. 73, no. 6, pp. 1796-1803, 2009.

[36] C. Gallage, R. Udukumburage, T. Uchimura, and T. Abeykoon, "Comparison of direct and indirect measured soil-water characteristic curves for a silty sand," International Journal of Geomate, vol. 13, no. 39, pp. 9-16, 2017. 